\title{
Synthesis of Multiwalled Carbon Nanotubes-Titania Nanomaterial for Desulfurization of Model Fuel
}

\author{
Tawfik A. Saleh, Mohammad N. Siddiqui, and Abdulrahman A. Al-Arfaj \\ Department of Chemistry and Center of Research Excellence in Nanotechnology (CENT), \\ King Fahd University of Petroleum \& Minerals, Dhahran 31261, Saudi Arabia \\ Correspondence should be addressed to Mohammad N. Siddiqui; mnahid@kfupm.edu.sa
}

Received 13 September 2014; Revised 18 October 2014; Accepted 18 October 2014; Published 6 November 2014

Academic Editor: Antonios Kelarakis

Copyright (C) 2014 Tawfik A. Saleh et al. This is an open access article distributed under the Creative Commons Attribution License, which permits unrestricted use, distribution, and reproduction in any medium, provided the original work is properly cited.

\begin{abstract}
This work reported on the development of novel nanomaterials of multiwalled carbon nanotubes doped with titania $\left(\mathrm{CNT}_{\mathrm{TiO}}\right)$ for the adsorptive desulfurization of model fuel oils. Various analytical techniques such as field emission scanning electron microscope (FESEM), energy dispersive X-ray spectroscopy (EDX), and Fourier transform infrared spectroscopy (FTIR) were used for the characterization of the nanomaterials. The initial results indicated the effectiveness of the prepared $\mathrm{CNT} / \mathrm{TiO}{ }_{2}$ nanomaterials in removing sulfur compounds from model fuel oil. The adsorption of DBT, BT, and thiophene from model fuel onto the derived sorbents was performed using batch mode system. These $\mathrm{CNT} / \mathrm{TiO}_{2}$ nanomaterials initially afforded approximately $45 \%$ removal of DBT, $55 \% \mathrm{BT}$, and more than $65 \%$ thiophene compounds from model fuels. The $\mathrm{CNT} / \mathrm{TiO}_{2}$ nanomaterials provided an excellent activity towards interaction with organosulfur compounds. More experiments are underway to optimize the parameters for the adsorptive desulfurization processes. We believe that these nanomaterials as adsorbents will find useful applications in petroleum industry because of their operational simplicity, high efficiency, and high capacity.
\end{abstract}

\section{Introduction}

The amount of sulfur contents in fuels often provides indication to the emission of $\mathrm{SO}_{x}$ gases, which are responsible for the formation of sulfates and acid. Moreover, several corrosion problems in pipelines, pumping, and refining equipment may also occur as a result of sulfur-contents emission. Sulfur emissions also cause deleterious effects on human health. In order to reduce the sulfur contents in diesel fuels, the environmental regulation agencies have introduced an allowable limit of $10 \mathrm{ppm}$ with the ultimate goal of further reducing $\mathrm{SO}_{x}$ gases emissions. As a result of the aforementioned environmental regulations, there have been several reports successfully reducing the organic sulfur contents in diesel fuels to less than $10 \mathrm{ppm}$. For instance, of the various desulfurization techniques, hydrodesulfurization (HDS), oxidative desulfurization, biodesulfurization, and adsorptive desulfurization are being investigated for their ability to produce clean fuels. One of the current industrial methods for removal of sulfur from fuels is HDS, for reducing of organic-sulfur in gasoline, diesel, and other intermediate distillates where various catalysts are used. HDS process removes many organosulfur compounds and their derivatives from transportation fuels; however, this method has certain limitations and is less effective at the removal of sterically hindered dibenzothiophene derivatives such as 4,6dimethyldibenzothiophene, which are most prominent in diesel fuels. Some suggestions such as the use of more active catalysts, longer residence times, and higher temperatures and pressures have been reported for improving the effectiveness of HDS for producing low sulfur product [1]. Therefore, to meet the demands of producing ultraclean fuels with lower than $15 \mathrm{ppm}$ of organosulfur compounds via HDS will increase both monetary investment and operational costs. Consequently, it is imperative that advanced technologies be developed for desulfurization at ambient temperature and pressure. Currently, the most common HDS alternative method used to achieve ultraclean fuels is adsorptive desulfurization (AD) where $\pi$-complexation is free of steric hindrance for adsorption [2-4]. 
One-dimensional nanoscale structure of nanotubes with covalent bonding together imparts unusual properties: high tensile strength, high resilience, and good thermal and mechanical stability. Porous carbon also has properties such as uniform and regular pore size and structure, chemically inert, pore network interconnected with tailorable surface properties [5]. Such properties make CNT a good adsorbent and catalyst support. Thus carbon nanotubes could be used as support in nanocomposite materials. Activated carbon has been reported [6] to have good adsorption ability toward methyl substituents of organic sulfur compounds such as 4,6DMDBT that is a refractory compound for desulfurization of diesel.

Adsorption of organic sulfur compounds in diesel fuel to composite adsorbents has been reported in recent years. A comparison between activated carbon, alumina, and MWNT and their corresponding composite catalysts with cobalt and molybdenum oxide and sulfide shows that dibenzothiophene (DBT) adsorbs to two kinds of sites, one is the acidic sites and another is on the transition metals with vacant orbits which can accept electrons. In case of sulfide state adsorbent, newly produced active sites on the edges of active phases provide higher adsorption compared with oxide states [7]. $\mathrm{Fe}_{2} \mathrm{O}_{3}$ NPs supported on CNT was employed as a catalyst for the desulfurization of $\mathrm{H}_{2} \mathrm{~S}$ in a classical fixed-bed configuration [8]. $\mathrm{Cs}_{2.5} \mathrm{H}_{0.5} \mathrm{PW}_{12} \mathrm{O}_{40} / \mathrm{MWNT}$ supported catalyst has been reported as effective catalyst for the oxidative removal of DBT, with high desulfurization efficiency [9]. However, the adsorption capability should depend on the quality of the interfacial contact between $\mathrm{CNT}$ and $\mathrm{TiO}_{2}$. Literature screening indicates that the carbon materials like carbon nanotubes, graphenes, and their composites are promising candidates for improving the activity of nanoparticles by preventing their agglomeration and thus maintaining their high surface area [10-15].

Some approaches have been reported for the synthesis and preparation of $\mathrm{TiO}_{2} / \mathrm{CNT}$ composite. This includes direct in situ growth, in situ CVD synthesis route, highintensity ultrasonic radiation method, assembling presynthesized metal oxide nanoparticles as building blocks on CNTs, spontaneous formation of metal oxide nanoparticles on CNTs, hydrothermal crystallization, sol-gel followed by spark plasma sintering process, surfactant wrapping sol-gel method, and chemical precipitation [16-19].

We report here a procedure for desulfurization of model fuel oil by adsorption on MWCNTs/TiO 2 nanomaterials. Thus, the nanomaterials were synthesized and characterized. The desulfurization activity was evaluated by model fuel of thiophene, benzothiophene, and dibenzothiophene.

\section{Experimental}

2.1. Materials and Chemicals. Multiwalled carbon nanotubes (CNTs) were with specifications of purity, >95\%; outer diameter, $30-50 \mathrm{~nm}$; inner diameter, $5-10 \mathrm{~nm}$; $30-50 \mathrm{~nm}$; length, $10-20 \mu \mathrm{m}$; average specific surface area, $60 \mathrm{~m}^{2} / \mathrm{g}$; electrical conductivity: $>100 \mathrm{~S} / \mathrm{cm}$; bulk density: $0.28 \mathrm{~g} / \mathrm{cm}^{3}$; true density: $\sim 2.1 \mathrm{~g} / \mathrm{cm}^{3}$. Thiophene, benzothiophene, and
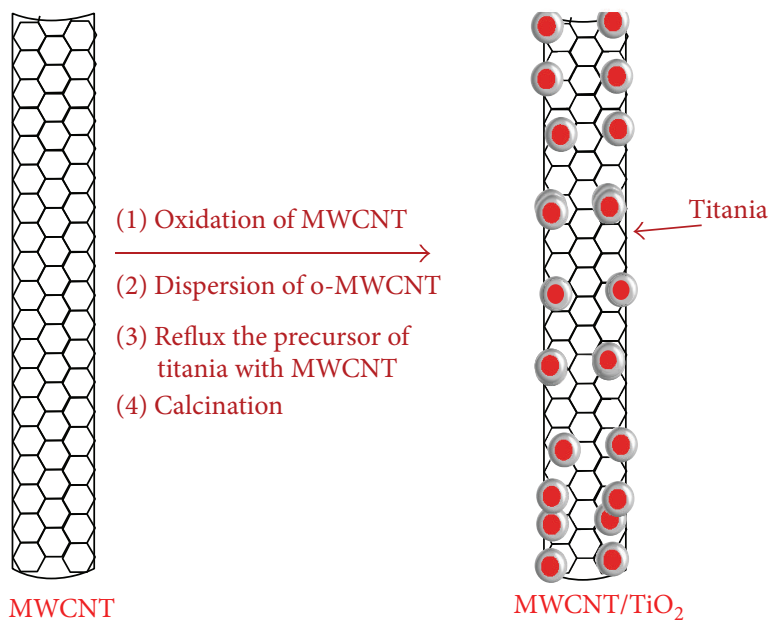

FIgUre 1: Schematic diagram of preparation of $\mathrm{MWCNT} / \mathrm{TiO}_{2}$ nanomaterials.

dibenzothiophene were obtained from Fisher Scientific Company. The solvents employed in all the studies were of high purity. Other reagents were of analytical purity, obtained from Sigma Aldrich and used as received.

2.2. Preparation of $\mathrm{CNT} / \mathrm{TiO}_{2}$ Nanomaterials. CNTs were purified and oxidized before use. After the purification process, nanotubes were treated with a mixture of $\mathrm{HNO}_{3}$ and $\mathrm{H}_{2} \mathrm{SO}_{4}$ as reported earlier $[20,21]$. In brief, nanotubes were refluxed in a mixture of $\mathrm{H}_{2} \mathrm{SO}_{4}-\mathrm{HNO}_{3}(3: 1)$ for $8 \mathrm{~h}$ at $120^{\circ} \mathrm{C}$. The mixture was diluted, filtered, and washed with deionized water to remove the excess acid from this solution. After that, it was dried overnight at $120^{\circ} \mathrm{C}$ in an oven, and then it was milled and crushed to powder.

$\mathrm{CNT} / \mathrm{TiO}_{2}$ nanomaterials were prepared by the following steps. Nanotubes were dispersed by sonication for $4 \mathrm{~h}$ at room temperature. At the same time the precursor of titania, titanium tetraisopropoxide solution, was hydrolyzed and stirred until it progressively became more viscous. The former, then, was drop-wise added with continuous stirring [22]. Then, it was refluxed for $6 \mathrm{~h}$. Then, the mixture was washed and filtered. Then, it was dried overnight. The final step is the calcination for $3 \mathrm{~h}$ at $350^{\circ} \mathrm{C}$. Then, the composite was characterized using various instruments. Figure 1 depicts a schematic diagram of $\mathrm{CNT} / \mathrm{TiO}_{2}$ nanomaterials preparation.

2.3. Characterization. The characterization of the $\mathrm{CNT} / \mathrm{TiO}_{2}$ nanomaterials is important to evaluate the interaction between titania nanoparticles and the nanotubes. Therefore, the characterization was performed by means of field emission scanning electron microscope (FESEM), energy dispersive X-ray spectroscopy (EDX), and Fourier transform infrared absorption spectroscopy (FTIR). The specific surface area of the $\mathrm{CNT} / \mathrm{TiO}_{2}$ nanomaterials was determined by the Brunauer-Emmett-Teller (BET) method using adsorption data in a relative pressure range from 0.05 to 0.4 . 


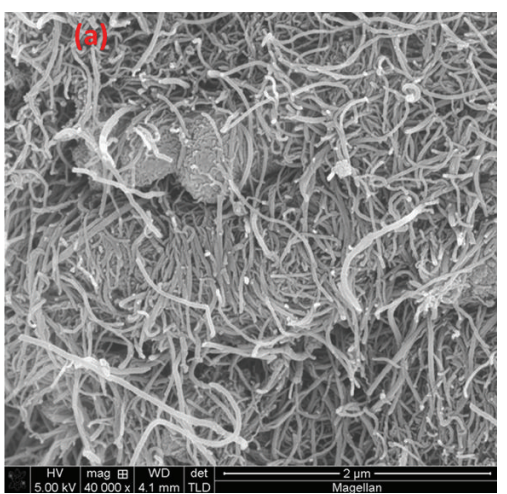

(a)

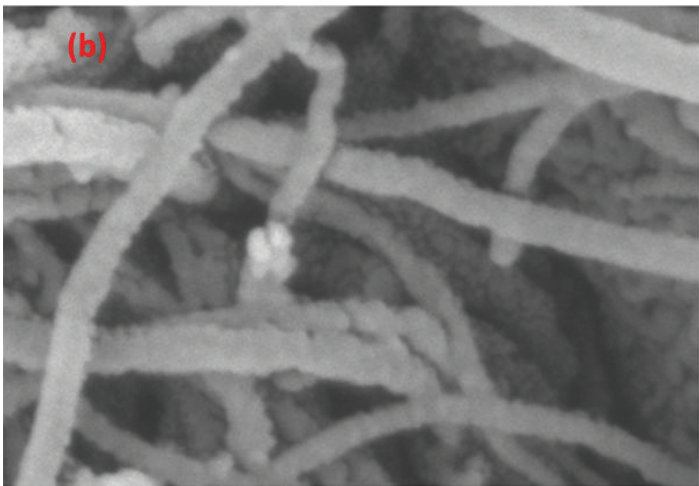

(b)

FIGURE 2: High resolution field emission scanning electron microscopy (FESEM) image (a) and enlarged SEM image (b) of the $\mathrm{MWCNT} / \mathrm{TiO}_{2}$ nanomaterials.

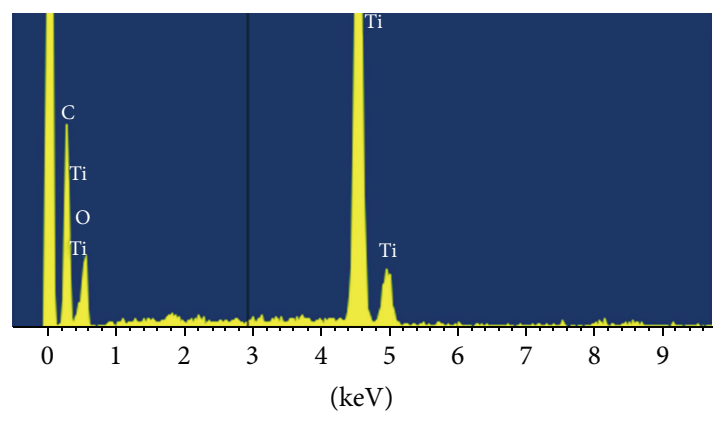

Full scale 291 cts cursor: 2.915 (6cts)

(a)

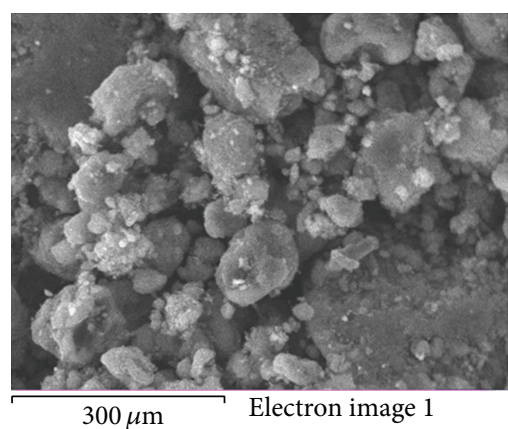

(b)

FIGURE 3: EDX spectrum and SEM image of the $\mathrm{MWCNT} / \mathrm{TiO}_{2}$ nanomaterials.

\section{Results and Discussion}

3.1. Characterization. The surface morphology of the prepared nanotubes/titania nanomaterials was characterized by high resolution field emission scanning electron microscope (SEM). The SEM image is depicted in Figure 2(a) and enlarged part of SEM image is depicted in Figure 2(b). The surface morphology of $\mathrm{TiO}_{2}$ nanoparticles is ball like round shape or spherical shape decorated on the nanotubes. Based on these findings, one can induce that the nanocomposite has been successfully obtained and titania nanoparticles were deposited on the surface of the nanotubes $[23,24]$.

The EDX analysis was also carried out for the synthesized $\mathrm{CNT} / \mathrm{TiO}_{2}$ nanomaterials. The EDX spectrum is depicted in Figure 3. The spectrum confirms the presence of the carbon, oxygen, and titanium elements, which formed the $\mathrm{CNT} / \mathrm{TiO}_{2}$ nanomaterials. Table 1 presents the elemental analysis of nanomaterial with weight and atomic percent. EDX analysis showed the presence of oxygen, nitrogen, carbon, and relatively high titanium content on the nanomaterials. Table 1 presents the elemental analysis of nanomaterial with weight and atomic percent.

The nitrogen adsorption-desorption measurement at $-160^{\circ} \mathrm{C}$ indicates that the prepared nanocomposites have a specific surface area of $158 \mathrm{~m}^{2} \cdot \mathrm{g}^{-1}$. These high surface and
TABLE 1: EDX elemental analysis of the $\mathrm{MWCNT} / \mathrm{TiO}_{2}$ nanomaterials.

\begin{tabular}{lcc}
\hline Element & Weight $\%$ & Atomic \% \\
\hline C K & 31.80 & 50.85 \\
O K & 27.29 & 32.76 \\
Ti K & 40.90 & 16.40 \\
\hline Totals & 100.00 & \\
\hline
\end{tabular}

rough surface morphologies are expected to enhance the adsorption for such applications. The molecular structure of nanomaterials was characterized by FT-IR as shown in Figure 4(a). The FTIR spectra of nanomaterials show that bands at 1580 and $1650 \mathrm{~cm}^{-1}$ are ascribed to the stretching vibrations of $\mathrm{C}=\mathrm{C}$ and $\mathrm{C}=\mathrm{O}$ on the nanotubes, respectively. The peaks at 1400 and $1100 \mathrm{~cm}^{-1}$ are ascribed with the $\mathrm{C}-\mathrm{O}$ stretching. The FTIR spectrum of nanomaterials shows the characteristic peak of $\mathrm{Ti}-\mathrm{O}$ bond at around $600-700 \mathrm{~cm}^{-1}$, and the characteristic peaks of carbonyl, hydroxyl, and unsaturated carbon bonds in the composite. [25, 26]. The structure of nanocomposite was characterized by XRD as shown in Figure 4(b). The XRD pattern of the $\mathrm{CNT} / \mathrm{TiO}_{2}$ nanomaterials confirms the presence of titania of anatase 


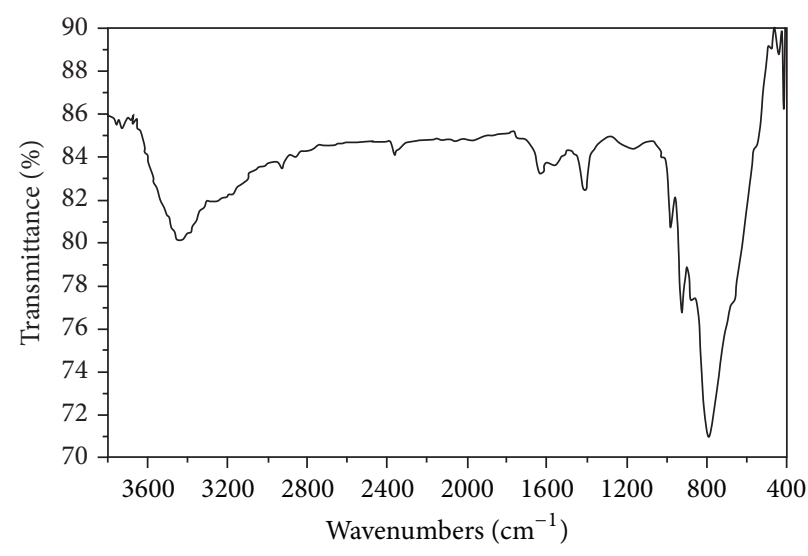

(a)

FIGURE 4: FTIR spectrum (a) and XRD

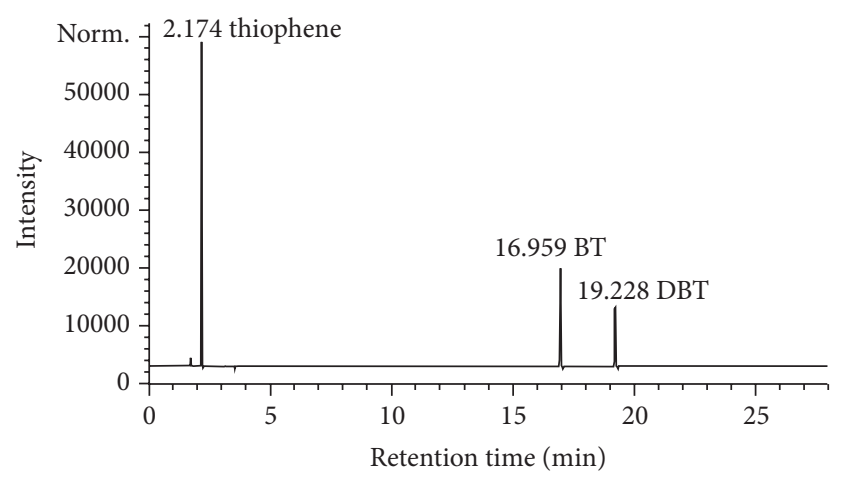

FIGURE 5: Gas chromatogram of desulfurized oil by $\mathrm{MWCNT} / \mathrm{TiO}_{2}$ nanomaterials; thiophene, benzothiophene (BT), and dibenzothiophene (DBT).

phase. The peak at $25.8^{\circ}$ correspond to the (002) reflection of CNTs and the anatase $\mathrm{TiO}_{2}$ peak (101) at the reflection plane of $2 \theta=25.3^{\circ}$. The peaks in the XRD pattern at $37.80(004)$, 48.18 (200), and 54.09 (105) clearly represent the anatase $\mathrm{TiO}_{2}$ phase. From the XRD pattern, it can be understood that the anatase constitutes the major crystal form in $\mathrm{CNT} / \mathrm{TiO}_{2}$ composite [27].

3.2. Desulfurization Activity. The work was conducted to evaluate the desulfurization activity of the $\mathrm{CNT} / \mathrm{TiO}_{2}$ nanomaterials. The desulfurization activity was evaluated by model fuel of thiophene, benzothiophene, and dibenzothiophene. Figure 5 depicts a shot screen of gas chromatogram of desulfurized oil by $\mathrm{CNT} / \mathrm{TiO}_{2}$ nanomaterials. The initial results revealed the effectiveness of the prepared nanomaterials in removing sulfur compounds from model fuel oil. From a comparison between the activity of CNT, titania mechanical mixture of titania and CNTs (MM), and the prepared $\mathrm{CNT} / \mathrm{TiO}_{2}$ nanomaterials, it was found that the $\mathrm{CNT} / \mathrm{TiO}_{2}$ nanomaterials have better desulfurization activity than others. Figure 6 depicts the results in percent. As shown

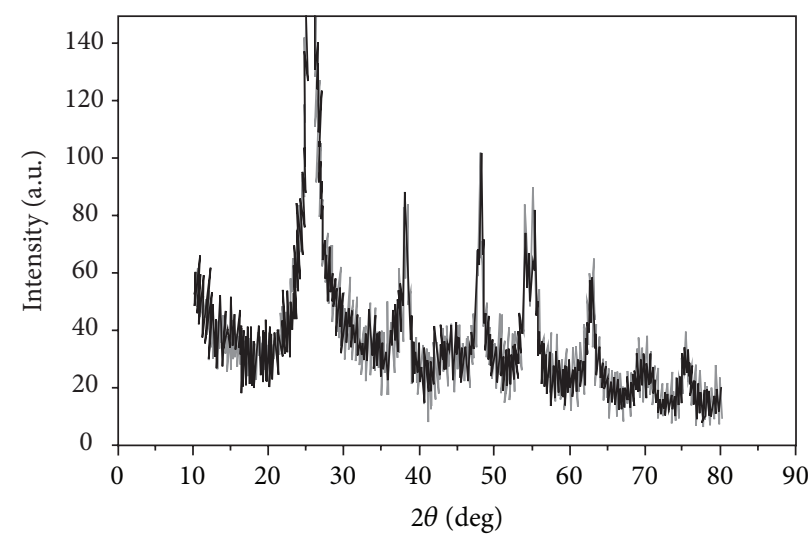

(b)

(b) of the $\mathrm{MWCNT} / \mathrm{TiO}_{2}$ nanomaterials.

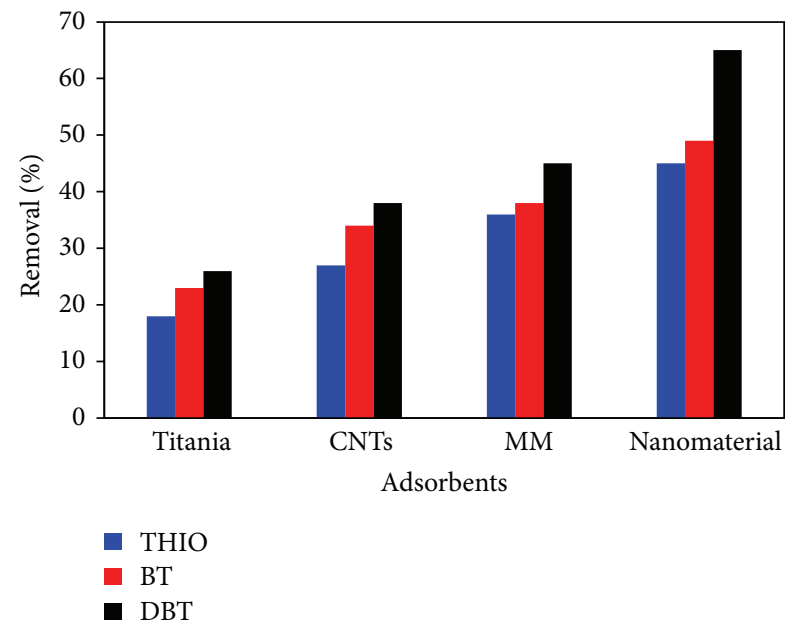

FIGURE 6: A comparison between the desulfurization activity of CNT, titania, mechanical mixture of titania and CNTs (MM), and the prepared $\mathrm{CNT} / \mathrm{TiO}_{2}$ nanomaterials; thiophene (THIO), benzothiophene (BT), and dibenzothiophene (DBT); conditions: reaction time is $60 \mathrm{~min}$; agitation speed is $150 \mathrm{rpm}$; temperature is $23^{\circ} \mathrm{C}$.

in the figure, the nanomaterials have better desulfurization activity; this can be explained by the fact that CNT as a support plays an important role in determining the nature and number of active sites and, consequently, in the activity of the nanoparticles. CNTs play also a role in inhibiting the in situ agglomeration/aggregation during the operation and thus help maintain the catalytic activity.

The efficiency of sulfur removal is significantly influenced by the amount of adsorbent used. The effect of the mass of adsorbents versus percentages of sulfur adsorbed was investigated for the $\mathrm{CNT} / \mathrm{TiO}_{2}$ nanomaterials. The amounts of thiophene, BT, and DBT adsorbed onto the adsorbents are depicted in Figure 7. A trend of increment in adsorption capacity with increment in adsorbent dose was observed from 0.1 to $0.75 \mathrm{~g}$. The results indicate that the amount of 


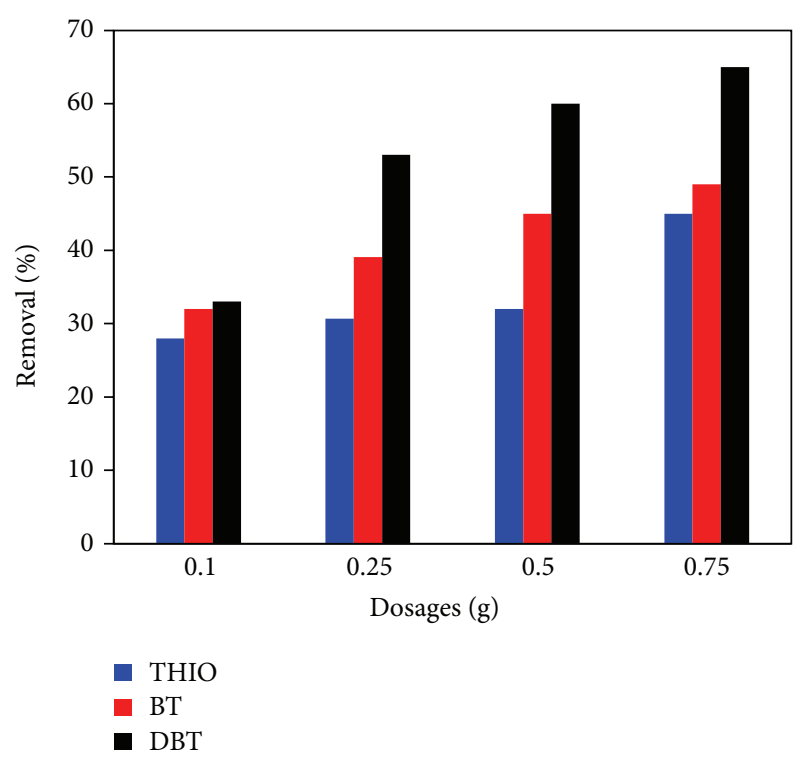

Figure 7: Effect of $\mathrm{CNT} / \mathrm{TiO}_{2}$ nanomaterials adsorbent dosage on the adsorption of thiophene (THIO), benzothiophene (BT) and dibenzothiophene (DBT).

sulfur compounds adsorbed by the adsorbent increased with increasing the amount of the adsorbent. The initial increase in adsorption capacity with increase in adsorbent dosage was expected because the increase in the number of adsorbent particles results in more surface area and more adsorption sites [28] available for sulfur compounds attachment.

DBT exhibits higher percentage of removal for each dosage and on all adsorbents due to the ability of DBT to form $\pi-\pi$ dispersive interactions between the aromatic ring in DBT and the nanotubes with nanoparticles. This also can explain that the molecules with three aromatic rings (DBT) showed a significantly higher adsorptive affinity than tworing aromatics (BT) and higher than one ring (thiophene) [29].

\section{Conclusions}

In summary, we have evaluated and compared the desulfurization activity of CNT, titania, mechanical mixture of titania and CNTs (MM), and the prepared $\mathrm{CNT} / \mathrm{TiO}_{2}$ nanomaterials for the adsorption of thiophene (THIO), benzothiophene (BT), and dibenzothiophene (DBT). It has been observed that prepared $\mathrm{CNT} / \mathrm{TiO}_{2}$ nanomaterials have better desulfurization activity than other tested materials. We believe the $\mathrm{CNT} / \mathrm{TiO}_{2}$ nanomaterials, as adsorbent, will find useful applications in petroleum industry because of their operational simplicity, high efficiency, and high capacity.

\section{Conflict of Interests}

The authors declare that there is no conflict of interests regarding the publication of this paper.

\section{Acknowledgment}

The authors would like to acknowledge the support provided by King Abdulaziz City for Science and Technology (KACST) through the Science \& Technology Unit at King Fahd University of Petroleum \& Minerals (KFUPM) for funding this work through project No. 12-PET3009-04 as part of the National Science, Technology and Innovation Plan (NSTIP).

\section{References}

[1] I. V. Babich and J. A. Moulijn, "Science and technology of novel processes for deep desulfurization of oil refinery streams: a review," Fuel, vol. 82, no. 6, pp. 607-631, 2003.

[2] F. Avilés, J. V. Cauich-Rodríguez, L. Moo-Tah, A. May-Pat, and R. Vargas-Coronado, "Evaluation of mild acid oxidation treatments for MWCNT functionalization," Carbon, vol. 47, no. 13, pp. 2970-2975, 2009.

[3] Z. Wang, M. D. Shirley, S. T. Meikle, R. L. D. Whitby, and S. V. Mikhalovsky, "The surface acidity of acid oxidised multi-walled carbon nanotubes and the influence of in-situ generated fulvic acids on their stability in aqueous dispersions," Carbon, vol. 47, no. 1, pp. 73-79, 2009.

[4] H. H. Cho, K. Wepasnick, B. A. Smith, F. K. Bangash, D. H. Fairbrother, and W. P. Ball, "Sorption of aqueous $\mathrm{Zn}$ (II) and Cd(II) by multiwall carbon nanotubes: the relative roles of oxygen-containing functional groups and graphenic carbon," Langmuir, vol. 26, no. 2, pp. 967-981, 2010.

[5] C.-M. Chang and Y.-L. Liu, "Functionalization of multi-walled carbon nanotubes with furan and maleimide compounds through Diels-Alder cycloaddition," Carbon, vol. 47, no. 13, pp. 3041-3049, 2009.

[6] V. K. Gupta, I. Ali, T. A. Saleh, M. N. Siddiqui, and S. Agarwal, "Chromium removal from water by activated carbon developed from waste rubber tires," Environmental Science and Pollution Research, vol. 20, no. 3, pp. 1261-1268, 2013.

[7] H. Shang, C. Liu, and F. Wei, "FT-IR study of carbon nanotube supported Co-Mo catalysts," Journal of Natural Gas Chemistry, vol. 13, no. 2, pp. 95-100, 2004.

[8] A. Deneuve, K. Wang, I. Janowska et al., "Bucky paper with improved mechanical stability made from vertically aligned carbon nanotubes for desulfurization process," Applied Catalysis A: General, vol. 400, no. 1-2, pp. 230-237, 2011.

[9] R. Wang, F. Yu, G. Zhang, and H. Zhao, "Performance evaluation of the carbon nanotubes supported $\mathrm{Cs}_{2.5} \mathrm{H}_{0.5} \mathrm{PW}_{12} \mathrm{O}_{40}$ as efficient and recoverable catalyst for the oxidative removal of dibenzothiophene," Catalysis Today, vol. 150, no. 1-2, pp. 37-41, 2010.

[10] Y.-J. Xu, Y. Zhuang, and X. Fu, "New insight for enhanced photocatalytic activity of $\mathrm{TiO}_{2}$ by doping carbon nanotubes: a case study on degradation of benzene and methyl orange," Journal of Physical Chemistry C, vol. 114, no. 6, pp. 2669-2676, 2010.

[11] Y. Zhang, Z.-R. Tang, X. Fu, and Y.-J. Xu, "TiO,-graphene nanocomposites for gas-phase photocatalytic degradation of volatile aromatic pollutant: is $\mathrm{TiO}_{2}$-graphene truly different from other $\mathrm{TiO}_{2}$-carbon composite materials?" ACS Nano, vol. 4, no. 12, pp. 7303-7314, 2010.

[12] M. Yang, N. Zhang, M. Pagliaro, and Y. Xu, "Artificial photosynthesis over graphene-semiconductor composites. Are we getting better?” Chemical Society Reviews, 2014. 
[13] N. Zhang, Y. Zhang, and Y.-J. Xu, "Recent progress on graphenebased photocatalysts: current status and future perspectives," Nanoscale, vol. 4, no. 19, pp. 5792-5813, 2012.

[14] M.-Q. Yang and Y.-J. Xu, "Selective photoredox using graphenebased composite photocatalysts," Physical Chemistry Chemical Physics, vol. 15, no. 44, pp. 19102-19118, 2013.

[15] C. Han, M. Q. Yang, B. Weng, and Y. J. Xu, "Improving the photocatalytic activity and anti-photocorrosion of semiconductor $\mathrm{ZnO}$ by coupling with versatile carbon," Physical Chemistry Chemical Physics, vol. 16, no. 32, pp. 16891-16903, 2014.

[16] Z. Li, B. Gao, G. Z. Chen, R. Mokaya, S. Sotiropoulos, and G. Li Puma, "Carbon nanotube/titanium dioxide $\left(\mathrm{CNT} / \mathrm{TiO}_{2}\right)$ core-shell nanocomposites with tailored shell thickness, CNT content and photocatalytic/photoelectrocatalytic properties," Applied Catalysis B: Environmental, vol. 110, pp. 50-57, 2011.

[17] T. A. Saleh, M. A. Gondal, and Q. A. Drmosh, "Preparation of a MWCNT/ZnO nanocomposite and its photocatalytic activity for the removal of cyanide from water using a laser," Nanotechnology, vol. 21, no. 49, Article ID 495705, 2010.

[18] T. A. Saleh, M. A. Gondal, Q. A. Drmosh, Z. H. Yamani, and A. AL-yamani, "Enhancement in photocatalytic activity for acetaldehyde removal by embedding $\mathrm{ZnO}$ nano particles on multiwall carbon nanotubes," Chemical Engineering Journal, vol. 166, no. 1, pp. 407-412, 2011.

[19] G. An, W. Ma, Z. Sun et al., "Preparation of titania/carbon nanotube composites using supercritical ethanol and their photocatalytic activity for phenol degradation under visible light irradiation," Carbon, vol. 45, no. 9, pp. 1795-1801, 2007.

[20] T. A. Saleh, S. Agarwal, and V. K. Gupta, "Functionalization of tungsten oxide into MWCNT and its application for sunlightinduced degradation of rhodamine B," Journal of Colloid and Interface Science, vol. 362, no. 2, pp. 337-344, 2011.

[21] T. A. Saleh, S. Agarwal, and V. K. Gupta, "Synthesis of $\mathrm{MWCNT} / \mathrm{MnO}_{2}$ and their application for simultaneous oxidation of arsenite and sorption of arsenate," Applied Catalysis B: Environmental, vol. 106, no. 1-2, pp. 46-53, 2011.

[22] T. A. Saleh, "The influence of treatment temperature on the acidity of MWCNT oxidized by $\mathrm{HNO}_{3}$ or a mixture of $\mathrm{HNO}_{3} / \mathrm{H}_{2} \mathrm{SO}_{4}$," Applied Surface Science, vol. 257, no. 17, pp. 7746-7751, 2011.

[23] D. Reyes-Coronado, G. Rodríguez-Gattorno, M. E. EspinosaPesqueira, C. Cab, R. de Coss, and G. Oskam, "Phase-pure $\mathrm{TiO}_{2}$ nanoparticles: anatase, brookite and rutile," Nanotechnology, vol. 19, no. 14, Article ID 145605, 2008.

[24] S. Chatterjee, A. Shit, and A. K. Nandi, "Nanochannel morphology of polypyrrole- $\mathrm{ZnO}$ nanocomposites towards dye sensitized solar cell application," Journal of Materials Chemistry A, vol. 1, no. 39, pp. 12302-12309, 2013.

[25] M. A. Chougule, G. D. Khuspe, S. Sen, and V. B. Patil, "Polypyrrole-ZnO nanohybrids: effect of CSA doping on structure, morphology and optoelectronic properties," Applied Nanoscience, vol. 3, no. 5, pp. 423-429, 2013.

[26] D. Juraj, K. Martin, B. Gabriela, K. Martin, and M. Iva, "Electrochemical fabrication and characterization of porous silicon/polypyrrole composites and chemical sensing of organic vapors," International Journal of Electrochemical Science, vol. 8, no. 2, pp. 1559-1572, 2013.

[27] T. A. Saleh and V. K. Gupta, "Photo-catalyzed degradation of hazardous dye methyl orange by use of a composite catalyst consisting of multi-walled carbon nanotubes and titanium dioxide," Journal of Colloid and Interface Science, vol. 371, no. 1, pp. 101-106, 2012.
[28] A. Srivastav and V. C. Srivastava, "Adsorptive desulfurization by activated alumina," Journal of Hazardous Materials, vol. 170, no. 2-3, pp. 1133-1140, 2009.

[29] J. Bu, G. Loh, C. G. Gwie, S. Dewiyanti, M. Tasrif, and A. Borgna, "Desulfurization of diesel fuels by selective adsorption on activated carbons: competitive adsorption of polycyclic aromatic sulfur heterocycles and polycyclic aromatic hydrocarbons," Chemical Engineering Journal, vol. 166, no. 1, pp. 207-217, 2011. 

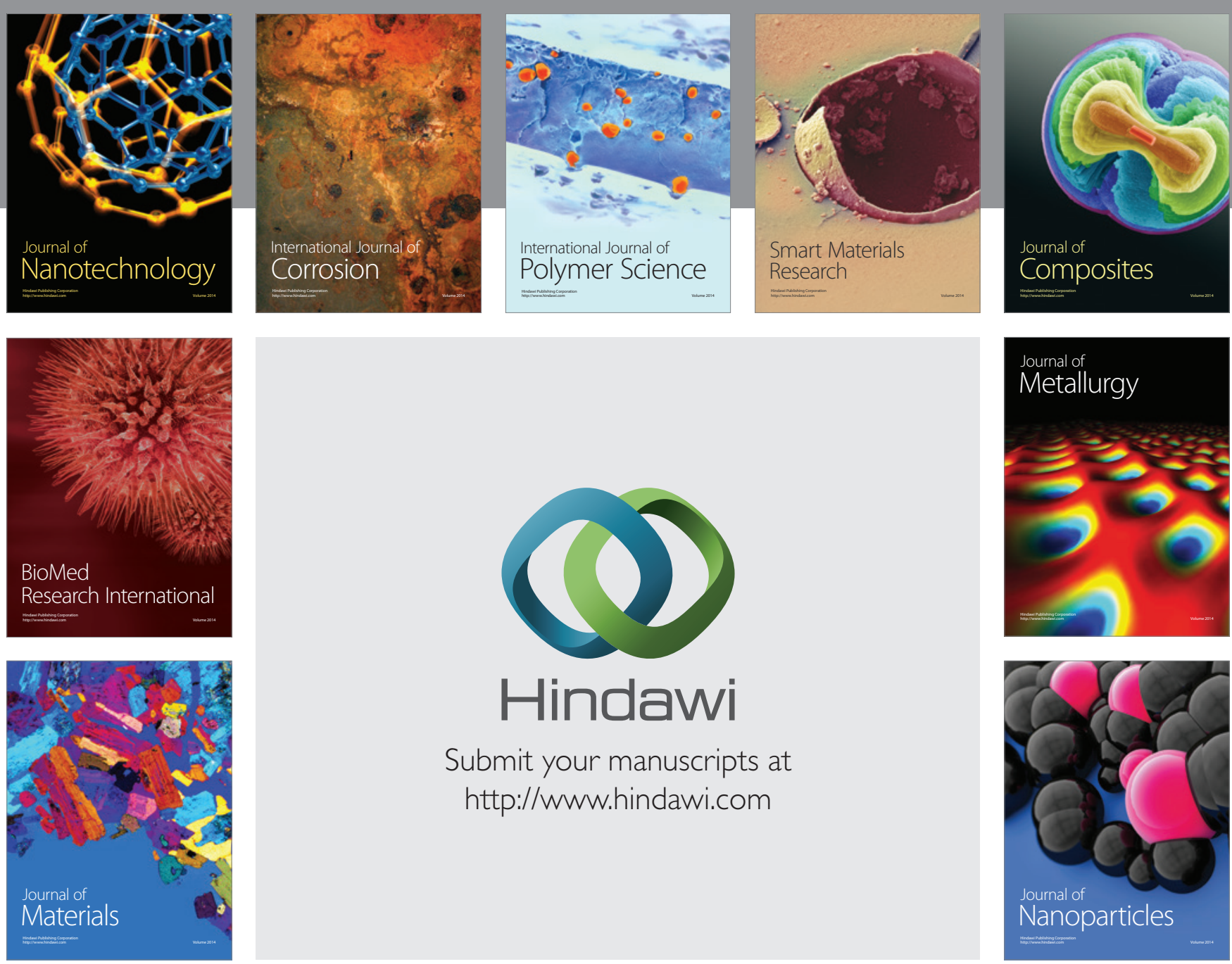

Submit your manuscripts at http://www.hindawi.com
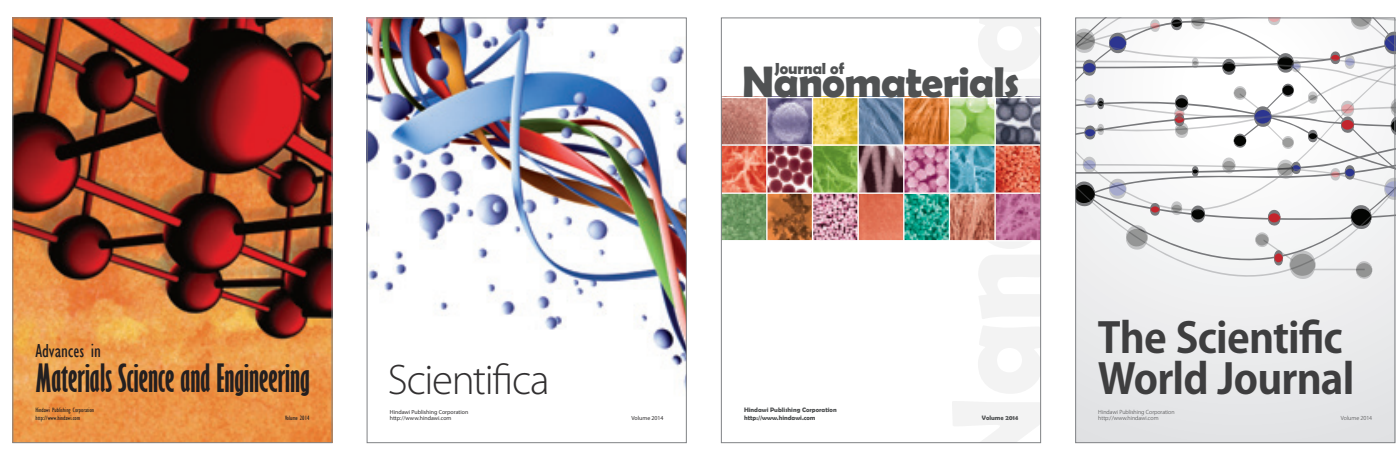

\section{The Scientific World Journal}
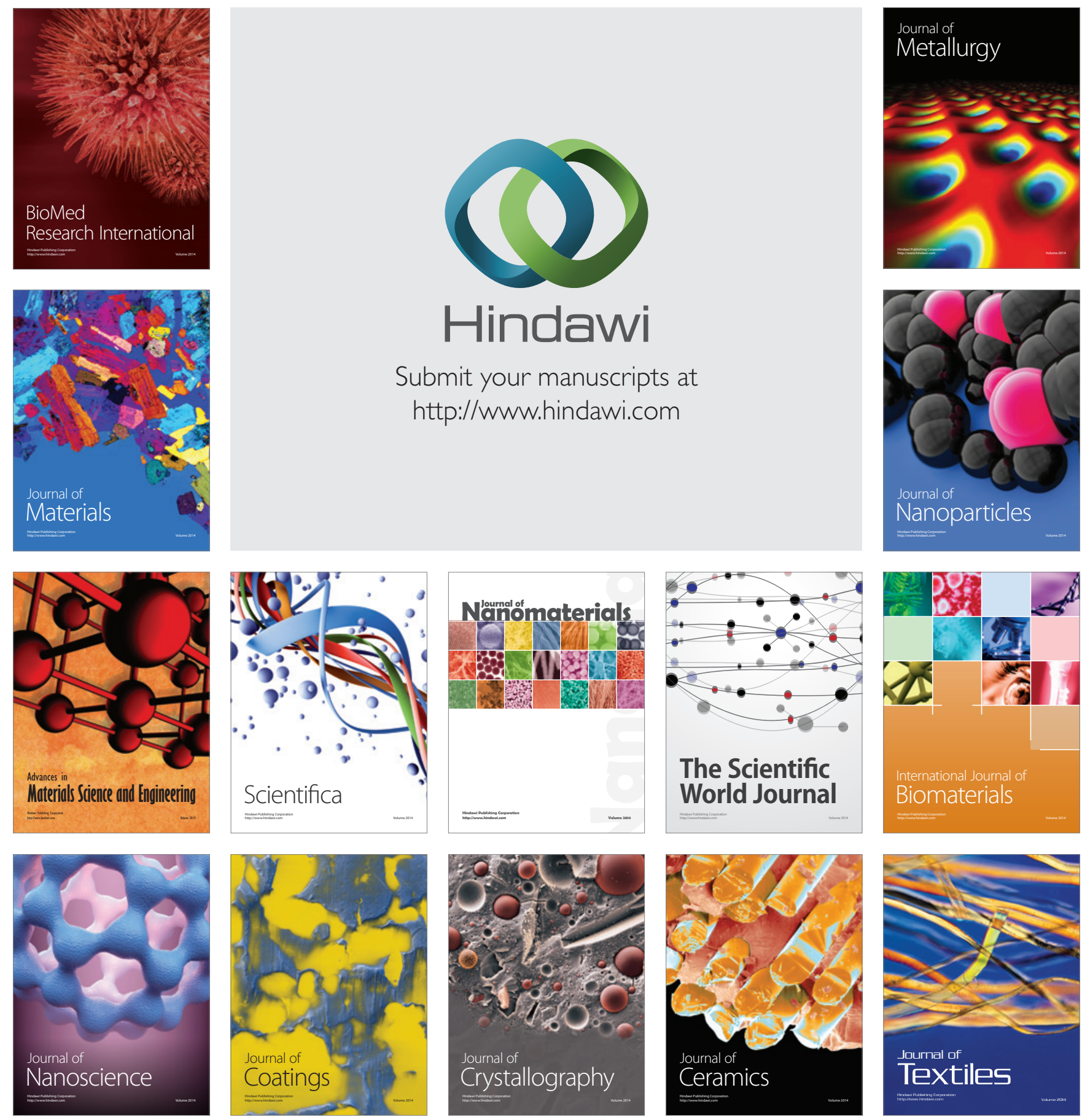